\title{
Correlations of Materials Surface Properties with Biological Responses
}

\author{
Robert E. Baier \\ Industry/University Center for Biosurfaces, 110 Parker Hall, State University of New York at Buffalo, Buffalo, NY, \\ USA \\ Email: baier@buffalo.edu
}

Received 21 November 2014; revised 21 December 2014; accepted 27 December 2014

Copyright (C) 2015 by author and Scientific Research Publishing Inc.

This work is licensed under the Creative Commons Attribution International License (CC BY).

http://creativecommons.org/licenses/by/4.0/

(c) (i) Open Access

\section{Abstract}

More than 50 years have passed since it was first recognized that the surface properties, and predominantly the surface energies of materials controlled their interactions with all biological phases via their spontaneous acquisition of proteinaceous "conditioning films" of differing degrees of denaturation but usually of the same substances within any given system. This led to the understanding that useful engineering control of such interactions could thus be manifested through adjustments to those surface properties, giving significant control and utility to the biomaterials developer without requiring detailed discovery of the biological specifications of the components involved. Thus, effective selection of adhesive versus abhesive (non-stick, non-retention) outcomes for such useful appliances as dental implants versus substitute blood vessels, or water-resistant bonded structures versus clean, nontoxic ship bottoms is now facilitated with little biological background required. A historical overview is presented, followed by a brief survey of the forces involved and most useful analyses applied. Utility for blood-contacting materials is described in contrast to utility for bone- and tissue-contacting materials, demonstrating practical uses in controlling cell-surface interactions and preventing biofouling. New research directions being explored are noted, urging applications of this prior knowledge to replace the use of toxicants.

\section{Keywords}

Surface Property, Biological Response, Adhesive, Blood-Contacting Materials

\section{Introduction}

Biological responses to non-physiological surfaces are, usually, mediated by spontaneous deposits of organic 
films and particulate matter from all biological fluids. The earliest events follow a common pattern. Such interactions result in differing degrees of bioadhesion and can be effectively correlated usually, even controlled by the surface properties, (especially surface energies) of the substrata involved [1].

There are convincing proofs of the bioengineering utility of surface property modification to minimize biological fouling [2]. Such proofs are found across the broad range of biomaterials development, from the successful implantation of substitute human blood vessels and total artificial hearts, to the fabrication of entirely nontoxic fouling-release coatings that can replace poison paints on ship bottoms. Surfaces contacting blood have received the most careful scrutiny, and first revealed the general features of biological response later found in other circumstances [3], like milk fouling of pasteurizers [4], oceanic fouling of heat exchangers [5], cell culture propagation [6] and dental plaque formation [7]. Control of the surface properties of biomaterials is a unifying approach to control of interactions between all that which is alive and all that which is not.

\section{Historical Overview}

It has been a successful strategy to tailor the surface properties of biomedical organ substitutes to exhibit desired degrees of biological response. As an example, general approval of the US Food and Drug Administration was granted as long ago as January, 1979 for human peripheral vascular reconstruction using tanned umbilical cord veins meeting specific surface properties and standards [8]. The natural pavements of endothelial cells of the original living blood vessels were lost during their processing from fresh or frozen umbilical cords [9]. What was preserved was mainly the surface quality of the sub-endothelial lining, a physiologically tolerable layer, along with a basement membrane and elastic internal lamina. The primary quality control criterion utilized was the "critical surface tension" parameter [10], adjusting processing conditions to maintain this value in the mid20 dynes/cm. The international experience included thousands of successful human implantations, saving numerous limbs from hitherto inevitable amputation [11].

In the occasional circumstances when properly surface-controlled materials do become coated with clotted blood, usually as a result of constriction of tubes at their connections or stagnation in the outflow tract, post-implantation analyses show the clots to reside innocently in the lumens of the vessels, exhibiting little to no adhesion to "biocompatible" walls [12]. Similar findings, and understanding, regarding materials surface properties in other settings will allow prediction and control of biological responses to materials in food processing units [13], in the sea [14], in tissue culture [15], in the womb [16], in the eye [17], and in the oral cavity [18].

\section{Background Concepts}

\subsection{Control of the Forces}

All inquiries about adhesive strengths and properties of biological deposits on various materials must include close control of the exposure geometries, flow fields and shear forces. The boundary hydrodynamics during both the deposition and detachment processes are crucial. It is not acceptable in biomaterials research, for example, to terminate a biological experiment (e.g. for the purpose of noting the accumulating microfouling films) by "rinsing" a sample in an unspecified or non-quantifiable manner [19]. Neither is it acceptable to equate the forces needed to detach or distract a biological deposit from a solid substratum with the thermodynamic strength of adhesion of the attached elements [20]. Cell and film separations from solids are not simply the reverse of the first attachment events. Joint failure upon separation is usually of the mixed-mode (cohesive and adhesive) type. Special devices for flow or shear-rate control should be employed during both the first exposure of test surfaces to biological media and in the final rinsing steps required to remove loosely held debris, co-adsorbed interfering salts, or entrained substances [21].

One can also incorporate transducers and electrodes into the circuits to record dynamic electrical events accompanying biological film deposition and adhesion of fouling elements. The technique of streaming potential measurement, for instance, allows direct calculation of the important boundary phase parameter of the plane of shear called zeta potential [22], cited in many theoretical models of biological responses to material samples.

\subsection{Selection of Surface Analyses}

Many techniques for rapid (and, in most cases, nondestructive) instrumental analysis of both synthetic material and biological surfaces are now available and in routine use. The sensitive procedure of multiple attenuated in- 
ternal reflection spectroscopy [23] produces infrared and/or UV/visible absorption spectra of the exterior molecular layers of matter defining biological interfaces with connecting solids. The acquired spectra reveal compositions, rates of accumulation, and modifications of such important boundary layers.

There are several sensitive, simultaneous or sequential analytical techniques immediately applicable to probing the structure and composition of thin biological deposits without requiring their manipulation or removal from the substrata of interest [24]. These techniques are: a) as described above, acquisition of infrared absorption spectra by the internal reflection technique; b) determination of film thicknesses and refractive indexes by the method of reflected polarized light (called ellipsometry); c) measurement of surface electrical states and contact potentials; d) inference of wettabilities, strengths of adhesion, operational surface free energies and critical surface tensions by comprehensive contact angle analysis (not just measurements of water contact angles!); e) morphological inspection of such layers by direct scanning electron microscopy without requiring over-coating the samples with obscuring metallic conducting films [25]; f) simultaneous analysis by energy-dispersive $\mathrm{X}$-ray techniques of the presence and relative abundances and locations of elements of atomic number higher than sodium [26], and g) identification of actual crystalline forms present, by glancing angle X-ray diffraction [27]. These methods have contributed significant information to the development of dental restorative composites, surgical adhesives, prosthetic implants, and extracorporeal circuits, as well as provided basic data on the initial events of blood clotting and marine fouling. The early addition of ESCA (Electron Spectroscopy for Chemical Analysis), also known as XPS (X-ray Photoelectron Spectroscopy) to the battery of methods was widely accepted [28].

\section{Basic Precepts}

\subsection{Blood-Contacting Materials}

The preferred materials of construction for pulsatile blood-handling devices are hardy elastomers of the polyether types of polyurethane, preferably fabricated to exhibit surface enrichment of "biocompatible" methyl groups [29]. These groups can be provided by direct alloying or admixture of polydimethylsiloxane (PDMS) in the original polymer blend [30]. All blood-contacting surfaces are preferably fabricated to be smooth and free of entrapped air prior to their first exposure to blood. Even with stringent preparation and precaution, the best synthetic materials for blood contact applications will still acquire spontaneously deposited plasma protein layers (usually dominated by fibrinogen)and support modest, though temporary, cellular adhesion [31].

Once this "conditioning" film is in place on mid-Critical Surface Tension (20 - 30 dynes/cm) materials with "passive" surface properties, arriving blood platelets that do attach typically maintain their natural discoid shapes [32]. They retain their granules and/or clotting factors. When in contact with higher or lower surface energy "active" materials, the platelets become distressed, undergoing a "viscous metamorphosis" that triggers both thrombosis and activation of the coagulation cycle. In all cases, segmented polymorphonuclear leucocytes, also called neutrophils, then stream toward the platelet- or platelet-debris-strewn foreign surfaces. On "active" incompatible surfaces, these perform as phagocytic units while white cells attach without any beneficial effect. Rather, the white cells add to the growing adherent cellular mass and accelerate the thrombotic episodes.

On "passive" compatible materials, selected by virtue of their less-retentive surface properties [33], the white cells function as a "clean-up squad", using fibrinolytic enzymes to break up the original fibrinogen films. Interfacial shear forces are then sufficient to detach the original bound mass, seldom to form again. Long-term, dynamic equilibrium with fresh flowing blood, then, is obtained through a more "native" plasma protein film acting as a "passivation" layer.

\subsection{Bone- and Tissue-Contacting Materials}

Basically, the operating rules for materials choices for bone- or tissue-contact devices are just the opposite of those for blood-contact devices, with a few interesting exceptions [34].

Biological mineral attachment to various materials has been demonstrated by the surface analytical techniques described earlier-including X-ray diffraction-to be dominated by calcium phosphate microcrystals of hydroxyapatite form. This basic mineral phase of bones and teeth has been grown, inadvertently, on flexible elastomeric and tissue materials used in artificial hearts and substitute heart valves [35]. Although this presents difficulties in tissue-valve and artificial heart development programs, where unwanted mineralization must be limited or 
overcome, one might seize upon this observation and turn adversity into virtue for use of similar materials in orthopedic or dental applications [36].

In the ongoing pursuit of improved surface conditions for dental implants of all types, including complicated structures that must interface with bone on one aspect, and overlying tissue on another, and protrude through the tissue interface into the oral cavity with an infection-free stable seal, coatings of the same elastomeric materials used in artificial hearts might be applied. Additional roughening and surface-activation would enhance cellular in-growth processes and stimulate osteogenesis [37].

The more conventional approach, using intrinsically high surface energy or bioactive materials, has meanwhile served quite well. This involved either the initial choice of self-cleansing (through surface dissolution or erosion in the host site) glass compositions [38], or calcium phosphate minerals, or the scrupulous prior cleansing (from metallic implants) of all organic debris and polishing agents. Their sterilization in the same process, and resultant activation for adhesion, is readily accomplished by exposure to radio-frequency-initiated glow discharges [39]. Apparatus to achieve such surface activation and cleansing is becoming generally available, and protocols require only a few minutes to execute [40]. Useful improvements in dental implant immobilization, encouragement of direct tissue binding, and elimination of fibrous encapsulation do result. Similar apparatus, scaled to handle larger implants such as artificial hips, can provide excellent surface cleaning and activation of these prostheses to enhance their cementation into prepared bone sites.

\section{Practical Use}

\subsection{Controlling Cell-Surface Interactions}

One of the interesting findings of microbiology has been that many hetero typically bound bacteria, isolated from oceanic films as well as from human dental plaque, often have filamentous tufts at one end specialized for preferential adhesion [41]. Internal reflection infrared spectra identifies the polar tuft material as being of mainly glycoprotein composition, at variance with the general hypothesis that lipoteichoic acid (a poly glycerol phosphate polymer) dominates the adhesive sites of those microorganisms.

Even such organisms, arguably specialized by evolution for colonization of any "foreign surface", can be denied successful adhesion (that is, there is no retention after gentle removal forces are applied). Proof of this requires only that one employ substrata exhibiting surface properties in the bioabhesive, or adhesion-resistant "biocompatible", zone identified long ago in studies dealing with mammalian cells [42]. The most utilitarian" surface energy conversion" coating of the sort required is that formed by covalent binding of methyl-silanes (often to create poly-dim ethylsiloxane layers) onto glass, silica, other mineral or metallic surfaces. Standard laboratory "siliconization" of glassware or metals can be excellent in this regard, but only when exposing new exterior chemical arrays of closely packed methyl groups to the colonizing bio-environment. Silicones not dominated by methyl group side chains do not resist bioadhesion [43]! Closely packed methyl group "lawns" exhibit a composite critical surface tension or apparent surface free energy of about 22 dynes per centimeter, in the minimally adhesive zone of the surface energy scale. The prevention of adhesion is mediated in these cases, nevertheless, by native structure persistence of deposited glycol proteinaceous films as discussed earlier [44].

Assuring specific biological responses to materials on the basis of their relative surface properties eventually will allow us to overcome still-troublesome biomaterials-centered infections. Early examples of the latter problem were those of pelvic inflammatory disease (PID) associated with Intrauterine Contraceptive Devices (IUDs) [45] having multi-filamentous nylon or frayed, micro-fibrillated polypropylene tail-strings. These structures provided sites for attachment and migration of infective microorganisms from the vaginal canal to the normally infection-free uterus, where they colonized as "biofilms" on other intrinsically bioadhesive materials used for the IUD bodies. Multimillion dollar legal judgments were levied against the major pharmaceutical firms that introduced these inappropriate biomaterials to the human reproductive system.

Unfortunately, the infection-related biomaterials problems diminished attention to beneficial features of earlier, more benign intrauterine contraceptive devices. The spontaneous coating of such devices by adsorbed glycoproteinaceous layers from the cervical mucus fluid supported speculation that such coatings may prevent the "capacitation" of sperm transiting the IUD locale. Sperm that do not experience such required changes in their initial surface (adhesive) properties do not successfully engage in another form of heterotypic adhesion, that of sperm-to-ovum, upon which fertilization of mammalian oocytes is premised. Again, the practical application of biomaterials with better-selected surface properties can make IUD regulation of fertility a useful, safe and effec- 
tive option for world-wide population control.

It is abundantly clear that "strength" of biological adhesion (more accurately, "resistance to detachment" or "strength of retention") is associated with defined ranges of surface energies, or critical surface tensions, for solid substrata in extremely diverse biological circumstances [46]. Other examples abound: demonstration that the minimum binding strength (resistance to detachment) for liver cells in tissue culture is sharply in the zone between 20 and 30 dynes/cm [47]; statistically sound observations, on solid substrata ranging in surface free energy from about 10 to over 50 dynes/cm (ergs per square centimeter), that the spread areas and associated degrees of distortion of settled human cells [48] and blood platelets, freshly obtained from plasmapheres is, are minimized in the critical surface tension zone between 20 and 30dynes/cm; observation of minimal forces required to pull musselbyssus discs from solid materials having these same critical surface tensions; and more. Even the induction of hemolytic damage to circulating red blood cells is minimized when the critical surface tensions of the walls of the shearing device are adjusted to the mid-20's dynes/cm range [49]. This last observation strongly implies that biological macromolecules that arrive at, and then are displaced from, solid surfaces of varying surface properties carry away with them (back into solution or suspension) varying "messages" based on their differing degrees of surface-contact-induced "denaturation" from their original solution states [50].

\subsection{Preventing Biofouling}

Biofouling refers to those unwanted deposits that frequently occur on contact lenses, dentures, periscope windows, and ship bottoms, to name just a few cases. A continuing difficulty in all food processing operations is the deposition of organic matter and mineral layers on the surfaces of heat exchangers and membranes. Dairy products are near the top of the list of problem-makers in this regard [51]. After many years of study, the predominant compositions of the first most strongly bound layers are generally not known. Differences of opinion still exist, for example, on whether the earliest deposits from raw milk are mainly proteins or minerals such as the calcium-phosphate-rich "milk stone". This is a fertile territory for biomaterials specialists to enter and enrich, using the same concepts of materials-related control of bioadhesion already successful in medical-device development.

For example, special flow cells may be designed to allow control of the surface shear rates and stresses, investigating the earliest fouling events for heated surfaces in contact with homogenized whole milk [52]. Preliminary results already available endorse the concept that milk protein adsorption is the first, essentially irreversible, event in surface fouling by dairy products, with mineral deposition occurring much later.

Useful flow cell devices have already been constructed [53]. Some apply "voltage clamping" circuitry so that the primary events of biofilm deposition and secondary events of microbial attachment, polymer exudation, and mineralization can be observed on substrata surfaces controlled electronically at any desired surface potential/charge condition. Such flow cells helped in documentation of the early events of microbiological fouling of model heat exchange surfaces in the warm subtropical waters of the Gulf of Mexico. Acquisition of that fundamental knowledge on biological fouling of heat exchange devices in warm seawater was of critical importance to international efforts to extract stored solar energy from the tropical oceans, using the principles of "ocean thermal energy conversion”. The Gulf of Mexico findings were compelling in their demonstration of slow deposition of humic-like conditioning films on the heat exchange surfaces. These adsorbed films were colonized in less than 3 days by pioneer bacteria of both flagellated and un-flagellated types. Within 6 days of exposure, growing deposits of polymer exudates were revealed around the pioneer microorganisms by using a special adaptation of scanning electron microscopy, eliminating the need for obscuring electro-conductive layers of sputtered metals. At the same exposure time, deposition of calcareous smatter, usually associated with diatoms and other algal forms, was noted. Patches of extreme microbiological diversity, with ecological succession already in progress, were observed on many test surfaces in the period between 3 and 6 days. It is certainly clear from these, and considerable supporting data, that biomaterials uses within that $70 \%$ of the earth's surface that is" wet” will require attention to (and control of) such biofouling phenomena [54].

Already gathered experimental data on critical inter facial layers of biological films in marine environments suggest nontoxic mechanisms by which their adhesion-or lack thereof to practical materials—can be controlled [55]. Recognizing serious drag-enhancing penalties associated with bacterial/slime fouling layers on even toxic marine paint surfaces, intriguing early results suggest that biofilms, or their synthetic analogues, maybe created to eliminate the drag effects of more-usual fouling layers and perhaps even to provide significant drag reduction 
[56]. Proof of-principle testing, using natural low-drag skin of living porpoises and killer whales [57], has shown the best surfaces have low-critical-surface-tension, protein-dominated characters inconsonance with similar findings for fouling-resistant layers of human oral mucosa and blood vessel endothelium [58]. Since synthetic materials for numerous biomedical devices have been successful without the need for toxicants to prevent fouling by even concentrated biological fluids, it should not be surprising that field tests endorsed similar material surface modifications for service in seawater. Results indicated that adjustment of a material's critical surface tension to the zone between 20 and 30 dynes/cm correlated with the most facile detachment of fouling debris [59]. The coincidence of this finding with results from tests of biomedical devices is encouraging in suggesting a strong conservatism among natural mechanisms promoting or preventing biological adhesion.

It even has been shown that algae produce base attachments of significantly greater area in order to resist separation from substrata having low critical surface tensions [60]. Diatom colonization success has also been demonstrated to be dependent on the initial surface energy of test substrata [61]. Our major conclusions must be that understanding, prediction, and control of surface properties of materials in all biological settings will be crucial to achieving improved performance in practical cases. Interestingly, here is a situation where large-scale (and large volume) commercial benefits may arise from the preceding "small science" (and small volume) of biomaterials development for artificial internal organs.

\section{New Research Directions}

Many authors still cite the needs for further study of the events of "fouling" in medical equipment, so it is only necessary to add some new discussion of the areas of biological adhesion noted here [62]. It is especially important to note the striking similarities in the fouling processes that occur in the bloodstream and the oral cavity, as similar to events in cooling water structures and processing equipment for various dairy products.

A need certainly still exists for improved understanding, on a basic level, of the deposition of macromolecules and of living cells at solid and semisolid (hydrogel, tissue) surfaces. Lack of the required detailed knowledge of these fundamental processes limits practical control of biological adhesion on a more general basis. Specific major areas for continuing study include the effects of different material surface properties (texture, charge, chemistry, energy) on binding of deposited macromolecules, seeking evidence for selective retention of particular components or sub fractions, determining the actual degree of coverage of the "cleaned" original surfaces, assessing the orientation of the adsorbed molecular entities, and defining the longer term modifications to the original surfaces' properties and to the attached molecules. Further, it is important to learn more about the cascade of specific cells arriving at and attaching to indwelling engineering materials, particularly noting cellular exudation of bio reactants or enzyme catalysts concentrated at the interfaces [63]. There is a known tendency for attached cells to produce polymeric exudates that both permanently bind them to the "pellicles" first acquired and engulf the growing, metabolizing units in "coats of slime". These events must be better understood and controlled if biomaterials-centered infections are to be successfully combatted [64].

It is also extremely important to extend modern surface analytical methods to the problems of identifying, more completely, the nature of cellular exopolymers produced, addressing as well their mode of production and changes with time and conditions. This is a crucial topic in many emerging sub-disciplines of what is generally called "biotechnology". The reactions between "exported" cellular products and the adsorbed, usually glycolproteinaceous, films that provide early binding of the cells to the starting surfaces must be ascertained. Improved measures of the actual strengths of adhesion (retention) between the cellular polymers and the films coating solid surfaces of differing physical chemical states must be developed. A practical focus of these efforts could be toward the identification of any "weak links" in the chain of cellular colonization, growth, and binding processes, that may be subject to direct interruption or strengthening [65].

Other biological responses to materials' surface properties are of equally urgent concern, specifically as they influence the events occurring at the initial attachment interfaces. It is recognized that cellular migration as well as other transport processes in tissue or fluid phases may limit the rate of cellular attachment to different engineering surfaces. The compositions, adhesive and cohesive strengths, and densities of the attached cell layers, as well as the geometries and hydrodynamic features at specific sites, are clearly important. These factors bear heavily on issues of human health and disease through their influence on the re-suspension and removal of biological deposits from the interfacial zones. Based upon the criteria reviewed here, one important lesson for fouling limitation in natural fluids may be that complete prevention of film formation and early cellular adhesion is 
not necessary: appropriate adjustments of material surface properties can control-indeed enhance or limit-the rate and reliability of re-entrainment of original deposits into the adjacent aqueous phases [66]. It is not yet known whether similar adjustments in materials' surface properties can modulate the biological responses of still-attached organisms to systemic (volume) agents for therapy or antisepsis.

Another identified research priority is for improvement and introduction of uniformity in testing methods regarding biological film deposition and cellular attachment, so that more direct comparisons of different materials in different circumstances can be made [67]. What seems to be required are small standardized units that can be adjusted to experience known flow rates, shear forces, nutrient conditions and so on, the purpose being to provide bio response indices with comparable meanings under different conditions at different times and at different sites. Availability and regular use of inexpensive, standardized test units would provide a continually expanding data base concerning the effects of material surface properties and treatments on rates of deposit formation, for example, under a variety of physical, chemical and biological conditions. More effective means of cleaning and sterilizing biomaterials surfaces are also required since it is obvious that current techniques, with the possible exception of still-emerging glow-discharge-plasma processes, are not likely to completely remove cellular and adsorbed film layers closest to the material surfaces [68]. When incomplete cleanliness is accepted, despite sterility, subsequent buildup of secondary fouling deposits occurs at rates much more rapid than that observed on truly clean substrata. Obviously, immunologic, antigenic, pyrogenic responses can still be triggered by remnants of even sterile biological debris. Thus, research directed at more complete removal of adherent deposits and their anchoring organic films, by both mechanical and chemical cleaning techniques, concomitant with or as a precursor to sterilization, is essential [69].

\section{Concluding Remarks}

Application of ambient environment as well as high-vacuum surface analytical techniques to biomaterials reveals fundamental similarities in the primary events of bioadhesion to them that are well correlated with the initial materials' surface properties. Initial fouling film formation in milk processing equipment exhibits a similar pattern to process in the oralcavity and in subtropical ocean water heat exchangers, including subsequent microorganism attachments, polymer exudation, and mineralization in most such circumstances. Implications of the identification of preferred surface energy ranges favoring or inhibiting permanent biological adhesion are clear in results from medical device trials including the artificial heart, dental implants, artificial hips, and substitute blood vessels. Calcification of blood-contacting surfaces of flexing elastomeric heart-assist-sacs indicates directions for similar methods to promote bone formation on dental or orthopedic fixtures [70]. Research priorities in the field of biological responses to materials surfaces should include additional attention to the effects of different surfaces on macromolecular retention, to the properties of various cells colonizing immersed surfaces, to the nature of exopolymers from cells attached to surfaces, to reactions between cellular products and surface "conditioning" films, to strengths of adhesion between cellular polymers and pre-adsorbed films, to transport processes in the bulk tissue or fluid phases, to the geometries and hydrodynamics of specific systems, and to selection of surface properties that will enhance the utility of chemical and mechanical techniques for removal of fouling films, while obtaining sterilization.

\section{References}

[1] Baier, R.E. (2006) Surface Behaviour of Biomaterials: The Theta Surface for Biocompatibility. Journal of Materials Science: Materials in Medicine, 17, 1057-1062. http://dx.doi.org/10.1007/s10856-006-0444-8

[2] Baier, R.E. (1982) Conditioning Surfaces to Suit the Biomedical Environment: Recent Progress. Journal of Biomechanical Engineering, 104, 257-271. http://dx.doi.org/10.1115/1.3138358

[3] Baier, R.E. and Dutton, R.C. (1969) Initial Events in Interactions of Blood with Foreign Surfaces. Journal of Biomedical Materials Research, 3, 191-206. http://dx.doi.org/10.1002/jbm.820030115

[4] Baier, R.E. (1981) Modification of Surfaces to Reduce Fouling and/or Improve Cleaning. Proceedings of Fundmentals and Applications of Surface Phenomena Associated with Fouling and Cleaning in Food Processing, Tylosand, 6-9 April 1981, 1-22.

[5] Baier, R.E. (1981) Early Events of Micro-Biofouling of All Heat Transfer Equipment. In: Somerscales, E.F.C. and Knudsen, J.G., Eds., Fouling of Heat Transfer Equipment, Hemisphere Publishing Corp, Washington, DC, 293-304.

[6] Baier, R.E. (1985) Cell Seeding: Biomaterial Surface Preparation. ASAIO Journal, 8, 104-108. 
[7] Baier, R.E. (1973) Occurrence, Nature, and Extent of Cohesive and Adhesive Forces in Dental Integuments. In: Lasslo A. and Quintana, R.P., Eds., Surface Chemistry and Dental Integuments, Charles C. Thomas Publisher, Springfield, 337-391.

[8] Baier, R.E., Akers, C.K., Perlmutter, S., Dardik, H., Dardik, I. and Wodka, M. (1976) Processed Human Umbilical Cord Veins for Vascular Reconstructive Surgery. Transactions-American Society for Artificial Internal Organs, 22, 514-524.

[9] Baier, R.E. (1978) Physical Chemistry of the Vascular Interface: Composition, Texture, and Adhesive Quality. In: Sawyer, P.N. and Kaplitt, M.J., Eds., Vascular Grafts, Appleton-Century-Crofts, New York, 76-107.

[10] Baier, R.E. and Loeb, G.I. (1971) Multiple Parameters Characterizing Interfacial Films of a Protein Analogue, Polymethylglutamate. In: Craver, C.D., Ed., Polymer Characterization: Interdisciplinary Approaches, Plenum Press, New York, 79-96.

[11] Dardik, H., Baier, R.E., Meenaghan, M., Natiella, J., Weinberg, S., Turner, R., Sussman, B., Kahn, M., Ibrahim, I. and Dardik, I.I. (1982) Morphologic and Biophysical Assessment of Long Term Human Umbilical Cord Vein Implants Used as Vascular Conduits. Surgery, Gynecology \& Obstetrics, 154, 17-26.

[12] Baier, R.E. and Abbott, W.M. (1978) Comparative Biophysical Properties of the Flow Surfaces of Contemporary Vascular Grafts. In: Dardik, H., Ed., Grafts Materials in Vascular Surgery, Symposia Specialists, Inc., Miami, 70-103.

[13] Baier, R.E. and Meyer, A.E. (1985) Surface Chemical Approaches to Decontamination and Disinfection. In: Lund, D., Plett, E. and Sandu, C., Eds., Fouling \& Cleaning in Food Processing, University of Wisconsin-Madison, Madison, 336-339.

[14] Baier, R.E. (1984) Initial Events in Microbial Film Formation. In: Costlow, J.D. and Tipper, R.C., Eds., Marine Biodeterioration: An Interdisciplinary Study, Naval Institute Press, Annapolis, 57-62. http://dx.doi.org/10.1007/978-1-4615-9720-9_8

[15] Baier, R.E. and Weiss, L. (1975) Demonstration of the Involvement of Adsorbed Proteins in Cell Adhesion and Cell Growth on Solid Surfaces. In: Applied Chemistry at Protein Interfaces, Advances in Chemistry Series, Vol. 145, American Chemical Society, Washington DC, 300-307.

[16] Baier, R.E. and Lippes, J. (1975) Glycoprotein Adsorption in Intrauterine Foreign Bodies. In: Applied Chemistry at Protein Interfaces, Advances in Chemistry Series, Vol. 145, American Chemical Society, Washington DC, 308-318.

[17] Baier, R.E. and Thomas, E.B. (1996) The Ocean: The Eye of the Earth. Contact Lens Spectrum, 37-44.

[18] Baier, R.E., Meyer, A.E., Natiella, J.R. and Carter, J.M. (1984) Surface Properties Determine Bioadhesive Outcomes: Methods and Results. Journal of Biomedical Materials Research, 18, 337-355. http://dx.doi.org/10.1002/jbm.820180404

[19] DePalma, V.A. and Baier, R.E. (1978) Microfouling of Metallic and Coated Metallic Flow Surfaces in Model Heat Exchange Cells. Proceedings of the Ocean Thermal Energy Conversion (OTEC) Biofouling and Corrosion Symposium, U.S. Department of Energy, PNL-SA-7115, Washington DC, 89-106.

[20] Baier, R.E. (1982) Comments on Cell Adhesion to Biomaterial Surfaces: Conflicts and Concerns. Journal of Biomedical Materials Research, 16, 173-175. http://dx.doi.org/10.1002/jbm.820160210

[21] Baier, R.E. and DePalma, V.A. (1979) Flow Cell and Method for Continuously Monitoring Deposits on Flow Surfaces. 8 Claims. U.S. Patent No. 4, 175, 233.

[22] Working Group on Physicochemical Characterization of Biomaterials, National Heart, Lung, and Blood Institute, National Institutes of Health, Leading to Publication of "Guidelines for Physico-Chemical Characterization of Biomaterials”, NIH Publication No. 80-2186, September 1980.

[23] Baier, R.E. and Zisman, W.A. (1970) Wettability and Multiple Attenuated Internal Reflection Infrared Spectroscopy of Solvent-Cast Thin Films of Polyamides. Macromolecules, 3, 462-468. http://dx.doi.org/10.1021/ma60016a017

[24] Baier, R.E., Shafrin, E.G. and Zisman, W.A. (1968) Adhesion: Mechanisms that Assist or Impede It. Science, 162, 1360-1368. http://dx.doi.org/10.1126/science.162.3860.1360

[25] Baier, R.E., Meyer, A.E., DePalma, V.A., King, R.W. and Fornalik, M.S. (1983) Surface Microfouling during the Induction Period. Journal of Heat Transfer, 105, 618-624. http://dx.doi.org/10.1115/1.3245630

[26] Baier, R.E., Forsberg, R.L., Meyer, A.E. and Lundquist, D.C. (2014) Ballast Tank Biofilms Resist Water Exchange but Distribute Dominant Species. Management of Biological Invasions, 5, 241-244. (Special ICAIS Issue) http://dx.doi.org/10.3391/mbi.2014.5.3.07

[27] Baier, R.E., Mack, E.J., Rogers, C.W., Pilie, R.J. and DePalma, V.A. (1981) Source Assessment of Atmospheric Aerosols: Spectroscopic Data from a Rapid Field Technique. Optical Engineering, 20, 866-872. http://dx.doi.org/10.1117/12.7972828

[28] Vargo, T.G., Hook, D.J., Gardella, J.A., Eberhardt, M.A., Meyer, A.E. and Baier, R.E. (1991) A Multitechnique Sur- 
face Analytical Study of a Segmented Block Copolymer Poly (Ether-Urethane) Modified through an $\mathrm{H}_{2} \mathrm{O}$ Radio Frequency Glow Discharge. Journal of Polymer Science Part A: Polymer Chemistry, 29, 535-545. http://dx.doi.org/10.1002/pola.1991.080290410

[29] Boretos, J.W., Pierce, W.S., Baier, R.E., Leroy, A.F. and Donachy, H.J. (1975) Surface and Bulk Characteristics of a Polyether Urethane for Artificial Hearts. Journal of Biomedical Materials Research, 9, 237-340. http://dx.doi.org/10.1002/jbm.820090308

[30] Pierce, W.S., Donachy, J.H., Rosenberg, G. and Baier, R.E. (1980) Calcification inside Artificial Hearts: Inhibition by Warfarin-Sodium. Science, 208, 601-603. http://dx.doi.org/10.1126/science.7367883

[31] Baier, R.E. and Kurusz, M. (2012) Understanding Blood/Material Interactions: Contributions from the Columbia University Biomaterials Seminar. ASAIO Journal, 58, 450-454. http://dx.doi.org/10.1097/MAT.0b013e3182631e3e

[32] Baier, R.E. (1987) Selected Methods of Investigation for Blood-Contact Surfaces. In: Leonard, E.F., Turitto, V.T. and Vroman, L., Eds., Blood in Contact with Natural and Artificial Surfaces, Annals of the New York Academy of Sciences, 516, 68-77. http://dx.doi.org/10.1111/j.1749-6632.1987.tb33031.x

[33] Baier, R.E., DePalma, V.A., Goupil, D.W. and Cohen, E. (1985) Human Platelet Spreading on Substrata of Known Surface Chemistry. Journal of Biomedical Materials Research, 19, 1157-1167. http://dx.doi.org/10.1002/jbm.820190922

[34] Baier, R.E., Meyer, A.E. and Natiella, J.R. (1992) Implant Surface Physics and Chemistry: Improvements and Impediments to Bioadhesion. In: Laney, W.R. and Tolman, D.E., Eds., Tissue Integration in Oral, Orthopedic, and Maxillofacial Reconstruction, Quintessence Publishing Co., Inc., Chicago, 240-249.

[35] Banas, M.D. and Baier, R.E. (2000) Accelerated Mineralization of Prosthetic Heart Valves. Molecular Crystals and Liquid Crystals Science and Technology, 354, 249-267. http://dx.doi.org/10.1080/10587250008023619

[36] Sendax, V.I. and Baier, R.E. (1992) Improved Integration Potential for Calcium-Phosphate-Coated Implants after Glow Discharge and Water Storage. Dental Clinics of North America, 36, 221-224.

[37] Baier, R.E. (1981) Catheter for Long-Term Emplacement. 8 Claims. U.S. Patent No. 4, 266, 999.

[38] Baier, R.E. (2002) A Challenging Anomaly_Glass that Does Not Clot Blood! The Glass Researcher, 12, $23-24$.

[39] Baier, R.E. and Meyer, A.E. (1988) Implant Surface Preparation. International Journal of Oral \& Maxillofacial Implants, 3, 9-20.

[40] Baier, R.E., Carter, J.M., Sorenson, S.E., Meyer, A.E., McGown, B.D. and Kasprzak, S.A. (1992) Radiofrequency Gas Plasma (Glow Discharge) Disinfection of Dental Operative Instruments, Including Handpieces. Journal of Oral Implantology, 18, 236-242.

[41] Glantz, P.O., Baier, R.E. and Christersson, C.E. (1996) Biochemical and Physiological Considerations for Modeling Biofilms in the Oral Cavity: A Review. Dental Materials, 12, 208-214. http://dx.doi.org/10.1016/S0109-5641(96)80024-8

[42] Baier, R.E. and DePalma, V.A. (1971) The Relation of the Internal Surface of Grafts to Thrombosis. In: Dale, W.A., Ed., Management of Arterial Occlusive Disease, Year Book Medical Publishers, Inc., Chicago, 147-163.

[43] Gould, J.A., Liebler, B., Baier, R., Benson, J., Boretos, J., Callahan, T., Canty, E., Compton, R., Marlowe, D., O’Holla, R., Page, B., Paulson, J. and Swanson, C. (1993) Biomaterials Availability: Development of a Characterization Strategy for Interchanging Silicone Polymers in Implantable Medical Devices. Journal of Applied Biomaterials, 4, 355-358. http://dx.doi.org/10.1002/jab.770040410

[44] Baier, R.E., Loeb, G.I. and Wallace, G.T. (1971) Role of an Artificial Boundary in Modifying Blood Proteins. Federation Proceedings, Federation of AmerSoc for Experimental Biol, Bethesda, Vol. 30, 1523-1538.

[45] Tietze, C. (1966) Contraception with Intrauterine Devices. American Journal of Obstetrics \& Gynecology, 96, 10431054.

[46] Glantz, P.O., Arnebrant, T., Nylander, T. and Baier, R.E. (1999) Bioadhesion-A Phenomenon with Multiple Dimensions. Acta Odontologica Scandinavica, 57, 238-241. http://dx.doi.org/10.1080/000163599428634

[47] Baier, R.E. (1980) Substrata Influences on the Adhesion of Microorganisms and Their Resultant New Surface Properties. In: Bitton, G. and Marshall, K.S., Eds., Adsorption of Microorganisms, Wiley-Interscience Publishers, Hoboken, 59-104.

[48] Baier, R.E. (1970) Surface Properties Influencing Biological Adhesion. In: Manly, R.S., Ed., Adhesion in Biological Systems, Academic Press, New York, 15-48. http://dx.doi.org/10.1016/B978-0-12-469050-9.50007-7

[49] Baier, R.E., Dutton, R.C. and Gott, V.L. (1970) Surface Chemical Features of Blood Vessel Walls and of Synthetic Materials Exhibiting Thromboresistance. In: Blank, M., Ed., Surface Chemistry of Biological Systems, Plenum Press, New York, 235-260. http://dx.doi.org/10.1007/978-1-4615-9005-7_14

[50] Baier, R.E. (1975) Blood Compatibility of Synthetic Polymers: Perspective and Problems. In: Kronenthal, R.L., Oser, 
Z. and Martin, E., Eds., Polymers in Medicine and Surgery, Plenum Press, New York, 139-159. http://dx.doi.org/10.1007/978-1-4684-7744-3_10

[51] Baier, R.E., DePalma, V.A., Meyer, A.E., King, R.W. and Fornalik, M.S. (1981) Control of Heat Exchange Surface Microfouling by Material and Process Variations. In: Chenoweth, J.M. and Impagliazzo, M., Eds., Fouling in Heat Exchange Equipment, HTD-Vol. 17, AmerSoc Mechanical Engineers, New York, 97-103.

[52] King, R.W., Meyer, A.E., Ziegler, R.C. and Baier, R.E. (1981) New Flow Cell Technology for Assessing Primary Biofouling in Oceanic Heat Exchangers. Proceedings of the 8th Ocean Energy Conference, U.S. Department of Energy, Washington DC, 431-436.

[53] Baier, R.E., Meyer, A.E. and King, R.W. (1988) Improved Flow-Cell Techniques for Assessing Marine Microfouling and Corrosion. In: Thompson, M.F., Sarojini, R. and Nagabhushanam, R., Eds., Marine Biodeterioration, Oxford \& IBH Publishing Co., Ltd., New Delhi, 385-394.

[54] Forsberg, R.L., Baier, R.E. and Meyer, A.E. (2014) Sampling and Experiments with Biofilms in the Environment: Part 2, Sampling from Large Structures Such as Ballast Tanks. In: Dobretsov, S., Thomason, J.C. and Williams, D.N., Eds., Biofouling Methods, Wiley-Blackwell, Oxford.

[55] Baier, R.E., Meyer, A.E. and Forsberg, R.L. (1997) Certification of Properties of Nontoxic Fouling-Release Coatings Exposed to Abrasion and Long-Term Immersion. Naval Research Reviews, 49, 60-65.

[56] Baier, R.E., Meyer, A.E., Forsberg, R.L. and Ricotta, M.S. (1997) Intrinsic Drag Reduction of Biofouling-Resistant Coatings. Proceedings, Emerging Nonmetallic Materials for the Marine Environment, U.S.-Pacific Rim Workshop Sponsored by the U.S. Office of Naval Research, Honolulu, 1-36 through 1-40.

[57] Baier, R.E., Gucinski, H., Meenaghan, M.A., Wirth, J. and Glantz, P.O. (1984) Biophysical Studies of Mucosal Surfaces. In: Glantz, P.O., Leach, S.A. and Ericson, T., Eds., Oral Interfacial Reactions of Bone, Soft Tissue \& Saliva, IRL Press Ltd, Oxford, 83-95.

[58] Baier, R.E. and Meyer, A.E. (1983) Surface Energetics and Biological Adhesion. In: Mittal, K.L., Ed., Physiochemical Aspects of Polymer Surfaces, Vol. 2, Plenum Publishing Corporation, New York, 895-909.

[59] Baier, R.E. (1973) Influence of the Initial Surface Condition of Materials on Bioadhesion. Proceedings, Third International Congress on Marine Corrosion and Fouling, Northwestern University Press, Evanston, 633-639.

[60] Fletcher, R.L. and Baier, R.E. (1984) Influence of Surface Energy on the Development of the Green Alga Enteromorpha. Marine Biology Letters, 5, 251-254.

[61] Meyer, A., Baier, R., Wood, C.D., Stein, J., Truby, K., Holm, E., Montemarano, J., Kavanagh, C., Nedved, B., Smith, C., Swain, G. and Wiebe, D. (2006) Contact Angle Anomalies Indicate that Surface-Active Eluates from Silicone Coatings Inhibit the Adhesive Mechanisms of Fouling Organisms. Biofouling, 22, 411-423. http://dx.doi.org/10.1080/08927010601025473

[62] Glantz, P.O.J., Arnebrant, T., Nylander, T. and Baier, R.E. (1999) Bioadhesion-A Phenomenon with Multiple Dimensions. Acta Odontologica Scandinavica, 57, 238-241. http://dx.doi.org/10.1080/000163599428634

[63] Baier, R.E. (1992) Influence of Surface and Fluid Conditions on Thrombus Generation. Proceedings of the Amer Acad of Cardiovascular Perfusion, 13, 143-146.

[64] Dutton, R.C., Webber, A.J., Johnson, S.A. and Baier, R.E. (1969) Microstructure of Initial Thrombus Formation on Foreign Materials. Journal of Biomedical Materials Research, 3, 13-23. http://dx.doi.org/10.1002/jbm.820030104

[65] Nayak, S.C., Baier, R.E., Meyer, A.E. and Abuhaimed, T. (2010) Improvement of Root Canal X-Ray Imaging by Delmopinol Pretreatment-Assisted Contrast Media Infiltration. Northeast Bioengineering Conference Proceedings, Columbia University, New York, 26-28 March 2010, ABS-026, 39.

[66] L’Italien, G.J., Megerman, J., Hasson, J.E., Meyer, A.E., Baier, R.E. and Abbott, W.M. (1986) Compliance Changes in Glutaraldehyde-Treated Arteries. Journal of Surgical Research, 41, 182-188. http://dx.doi.org/10.1016/0022-4804(86)90023-5

[67] Meyer, A.E., King, R.W., Baier, R.E. and Fornalik, M.S. (1985) A Field Study of Fouling of Test Surfaces Exposed to Flowing Brackish River Water. Proceedings, Condenser Biofouling Control Symposium, Electric Power Research Institute.

[68] Baier, R.E., Meyer, A.E., Akers, C.K., Natiella, J.R., Meenaghan, M.A. and Carter, J.M. (1982) Degradation Effects of Conventional Steam Sterilization on Biomaterial Surfaces. Biomaterials, 3, 241-245. http://dx.doi.org/10.1016/0142-9612(82)90027-8

[69] Park, J.H., Olivares-Navarrete, R., Baier, R.E., Meyer, A.E., Tannenbaum, R., Boyan, B.D. and Schwartz, Z. (2012) Effect of Cleaning and Sterilization on Titanium Implant Surface Properties and Cellular Response. Acta Biomaterialia, 8, 1966-1975. http://dx.doi.org/10.1016/j.actbio.2011.11.026

[70] White, J.A., Baier, R.E., Meyer, A.E., Burke, R.P. and Hausmann, E.M. (2000) Biomechanical and Biochemical Paths to Dystrophic Mineralization of Stented Cardiovascular Tissues. In: Vossoughi, J., Kipshidze, N. and Karanian, J.W., Eds., Stent Graft Update, Chapter 5, Medical and Engineering Publishers, Inc., Washington DC, 37-65. 
Scientific Research Publishing (SCIRP) is one of the largest Open Access journal publishers. It is currently publishing more than 200 open access, online, peer-reviewed journals covering a wide range of academic disciplines. SCIRP serves the worldwide academic communities and contributes to the progress and application of science with its publication.

Other selected journals from SCIRP are listed as below. Submit your manuscript to us via either submit@scirp.org or Online Submission Portal.
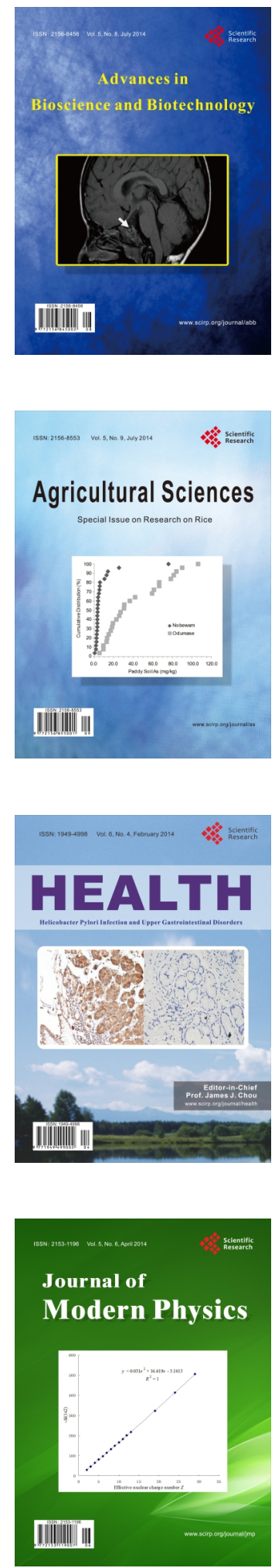
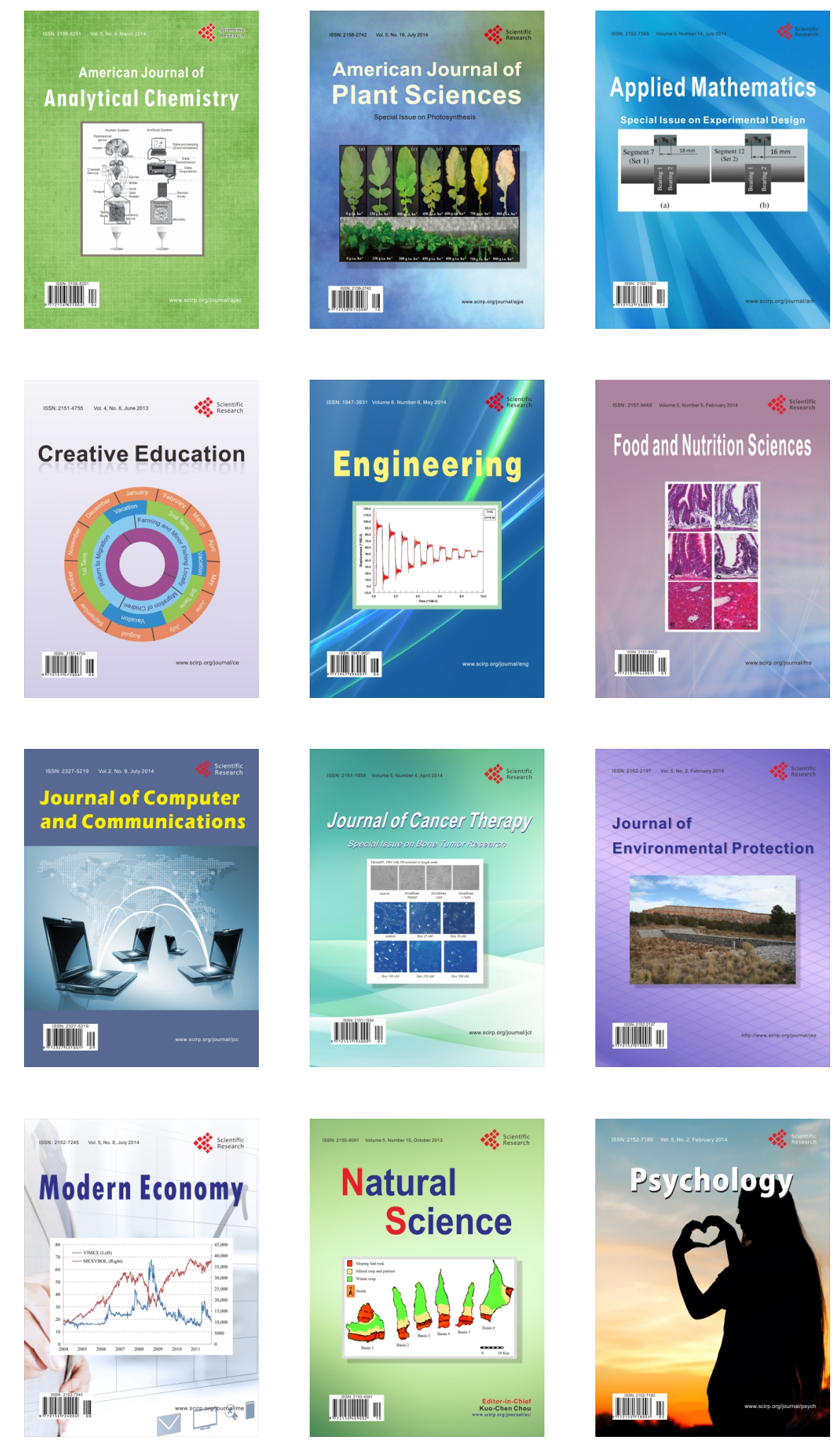